\title{
Nurturing Brilliance in Engineering: Creating Research Venues for Under- graduate Underrepresented Minorites in Engineering as an Initiative from Faculty Members that Foster Academic Inclusion, Development, and Post- graduation Instruction (Work in Progress)
}

\section{Dr. Eleazar Marquez, Rice University}

Eleazar Marquez is an Assistant Teaching Professor in the Department of Mechanical Engineering at Rice University.

\section{Dr. Samuel Garcia Jr., Texas State University}

Dr. Samuel García Jr. currently serves as Educator Professional Development Specialist at the Jet Propulsion Laboratory in Pasadena, CA and is an Assistant Professor of Practice for the LBJ Institute for Education and Research at Texas State University. 


\section{Nurturing Brilliance in Engineering: Creating Research Venues for Undergraduate Underrepresented Minorities in Engineering as an Initiative from Faculty Members that Foster Academic Inclusion, Development, and Post-graduation Instruction}

In this study, a new model for attracting, advancing, and advocating for the participation of underrepresented minorities in research venues is proposed with the intention of fostering academic inclusion, development, and post-graduation mentorship. It involves developing and nurturing a disposition from faculty by proactively identifying students via classroom interaction, performance, and academic aptitude and extending a personal invitation to collaborate on the research team. Current research opportunities for engineering undergraduates at tier-one institutions are obtained by students' incentive to communicate with faculty members via email or office hours. Despite the available opportunities, only a limited number of students are selected to participate due to the finite space and a degree of competency within the desired group. As for underrepresented minorities, such as Latino and African American students, these types of venues may seem inaccessible since a large number are first-generation college students who encounter supplementary challenges due to their cultural background, lack of proper academic guidance, and other institutional-based factors. These challenges oftentimes hinder their exposure, access, and participation to such academic resources that are necessary components for securing employment post-graduation or establishing fundamental research knowledge for graduate school. In the process of performing research, the faculty member serves as a mentor by providing extensive technical guidance and offer emotional support to strengthen academic development while simultaneously advocating post-graduation career venues. In a piloted study, the proposed model was implemented by a faculty member in a small private university in Texas to proactively identify and recruit engineering students into his research group. Primary results indicate that all recruited students identified as underrepresented minorities and that the faculty advisor provided mentorship regarding summer internships, graduate school, and industry related topics. These emerging findings attest to the importance of faculty members' desire and professional responsibility to outreach directly with the students and establish culturally responsive pathways for engaging diverse students in research opportunities.

\section{BACKGROUND AND MOTIVATION}

The number of STEM undergraduate students engaging in research opportunities is rather significant given its immediate and long-term benefits [2], [5], [14]. According to a survey conducted by Russell in 2006, 53\% of all STEM majors are involved in some form of research activity throughout their undergraduate matriculation [1], [3]. Studies reveal that participating in undergraduate research venues is notably beneficial towards nurturing academic development and clarifying career options post-graduation [14], [15]. In a follow-up survey conducted by the National Science Foundation (NSF), 88\% of its respondents, which held undergraduate research positions, reported significant growth in structuring and conducting a research project, 83\% expressed greater confidence in research and professional abilities, and $73 \%$ attested awareness of a graduate school environment [3], [4], [16]. These undergraduate research opportunities, according to Hurtado et al. [2], have further facilitated the decision of its participants to pursue 
STEM careers and Ph.D. studies post-graduation [14]. Mogk and Tomovic reported that partaking in undergraduate research opportunities is considered an effective educational tool which enhances the overall undergraduate experience [22], [23]. Such tool has proven to increase the pursuit of STEM degrees and graduate education for every ethnic group [24], [25], [26]. Bauer and Bennett further reported that participating in research venues improves skills such as speaking effectively, carrying out research assignments, and acquiring and interpreting data [27].

Knowing the immediate and long-term benefits research venues has on STEM education, particularly in fostering scientific and technological advancements, federal and private agencies have arduously invested in structuring academic and mentorship programs that attract undergraduate students to such opportunities [6], [19], [20]. Numerous initiatives such as summer programs, outreach venues, networking conferences, social activities, and financial programs to stimulate interest in STEM related fields [21]. The Minorities Opportunities in Research (MOR) program, for instance, is a program which has been structured with the intention of providing underrepresented students an opportunity to enhance their academic and personal skills through professional development sessions, assigned mentors, and tuition assistance. Thus, it has been revealed by Lopatto and Gasiewski et al. that underrepresented minorities participating in undergraduate research venues build stronger connections amongst their peers and overcome additional academic challenges such as racial and cultural isolation [9], [10].

Despite the numerous academic and personal benefits undergraduate research opportunities encapsulate, studies identify two areas of major improvement in such venues: 1) effective faculty guidance and mentorship [3], and 2) number of underrepresented minorities engaged in research opportunities [2]. Russell et al. reported that undergraduate programs can indeed ameliorate by an increase, and more effective, faculty guidance regarding academic development and career instruction post-graduation [1], [3]. The study alludes that not every student participating in undergraduate research receives constructive faculty mentorship and guidance in such critical areas. Thus, it cannot be assumed that participating in such initiatives will automatically position students for immediate and long-term academic success. The faculty member must devote time to delineate a range of possible career paths or research alternatives that will facilitate the decisionmaking.

The second area of major improvement in undergraduate research venues is the startling representation of underrepresented minorities. Minority groups such as African American (3.8\%), Latino $(4.1 \%)$, and Native American $(0.4 \%)$ constitute the largest underrepresented communities pursuing advanced degrees in STEM disciplines compared to other ethnic groups [6]. Although studies have concluded that undergraduate research opportunities serve as a tool for underrepresented minorities to remain in STEM fields [19], [20], the percentages remain relatively small. Such evident gap may be the rationale behind the staggering number of minority leaders involved in STEM related fields. According to Funk and Parker, the Black community compromises $9 \%$ of all STEM workers, while $7 \%$ of the total STEM population is represented by the Hispanic community [11]. These alarming statistics, in the context of undergraduate research opportunities, reveal that the number of underrepresented minorities conducting research might be even lower than those pursuing graduate school. Hurtado et al. and Allen suggest that the gap may further be associated with cultural and academic isolation, low expectations, and negative stereotypes in their surrounding undergraduate environment [2], [6]. 
In addition, research suggest that underrepresented students who fail to pursue STEM fields attributes to the absence of quality education and opportunities. The Pew Research Center (2018) studied perceived reasons why Black and Hispanic women fail to pursue STEM related fields [18]. They concluded that $42 \%$ of such demographic groups did not contemplate STEM fields due to the inaccessibility to quality education, while $41 \%$ were not encouraged to pursue STEM related careers from an early age. Thus, students graduating from more affluent communities have a greater academic advantage given their top quality secondary educational programs in science and math. As a result, underserved students of color find it difficult to adapt to the cultural and academic rigor of elite engineering programs.

As such, numerous government and academic programs have been established to promote diversity in higher education and increase the number of underrepresented minorities in research efforts [7], yet the number of participants continues to remain relatively low. This persistent gap may further attribute to the faculty demographics constituted in higher education, particularly, since underrepresented students are generally inclined towards seeking faculty advisors from their own ethnicity [13]. According to the U.S. Department of Education, faculty from African American, Hispanic, and American Indian heritage hold the lowest percentages amongst the faculty ranks [12]. 6.3\%, 5.6\%, and 3.6\% of African Americans hold Assistant Professor, Associate Professor, and Full Professor ranks, respectively, while Hispanics hold 4.3\%, 3.9\%, and $2.9 \%$ of the corresponding faculty ranks, and $0.4 \%, 0.4 \%$, and $0.3 \%$ of American Indians occupy the equivalent positions [12]. Chavous et al. from the University of Michigan reported that underrepresented minorities have a strong inclination towards finding a same-race mentor since it promotes a stronger sense of belonging and a higher academic efficacy [13]. According to such research findings, people who possess the same ethnic background have exceptional communication, understand each other better, and eliminate cultural hardships [13].

\section{PROPOSED WORK}

However, the authors of this paper observe a drastic disconnection between the established programs and the institutional culture and more specifically, the ability and desire of faculty members to include underrepresented students into their groups. Current research opportunities for engineering undergraduates at tier-one institutions are obtained by students' incentive to communicate with faculty members via email or office hours rather than faculty members proactively searching and recruiting hidden talent. Despite the available opportunities, only a limited number of undergraduate students are selected to participate due to various reasons such as group size, e.g. number of graduate students/post-doctoral fellows, or the degree of competency within a group.

As for underrepresented groups, such as Latino and African American students, these types of research venues may seem inaccessible, particularly since a large number are first-generation college students who encounter supplementary challenges due to a tension between their cultural background and mainstream institutional culture, unfamiliarity with availability of institutional resources, lack of proper academic guidance, and other institutional-based factors. These challenges oftentimes hinder their exposure, access, and participation to such academic resources that are necessary components for securing employment post-graduation or establishing fundamental research knowledge for graduate school. According to a study conducted at Rice University, entering freshmen with pre-matriculation credits are 50\% more likely to participate in undergraduate than those entering without any credits [28]. This alarming statistic reveals the 
absence of participation of underrepresented groups in research venues, particularly, since numerous underserved students initiate their college education without pre-matriculation credits. The College Board reported that $4.3 \%$ of the Black community and $22.9 \%$ of the Hispanic community scored a 3 or higher in Advanced Placement exams compared to 55.6\% of the White community.

As such, the authors propose a new model for attracting, advancing, and advocating for the participation of underrepresented individuals and groups in research venues with the intention of fostering academic inclusion, development, and post-graduation mentorship (Figure 1). The model was designed based on meticulous observations on current institutional practices, programs, and protocols, which promote the participation of underrepresented students in engineering research venues, and the current faculty stance to accept undergraduate students into their research groups. This emerging model, termed IBIEE (e.g., acronym for Identify, Build, Integrate, Evaluate, Extend), is centered on nurturing a disposition from faculty advisors to proactively identify and recruit engineering students into their groups. It includes five major components: 1) identify diverse students in classroom setting, 2) build relationships, 3) inquire about short and long-term academic interest, 4) evaluate academic interest, and 5) extend invitation to participate.

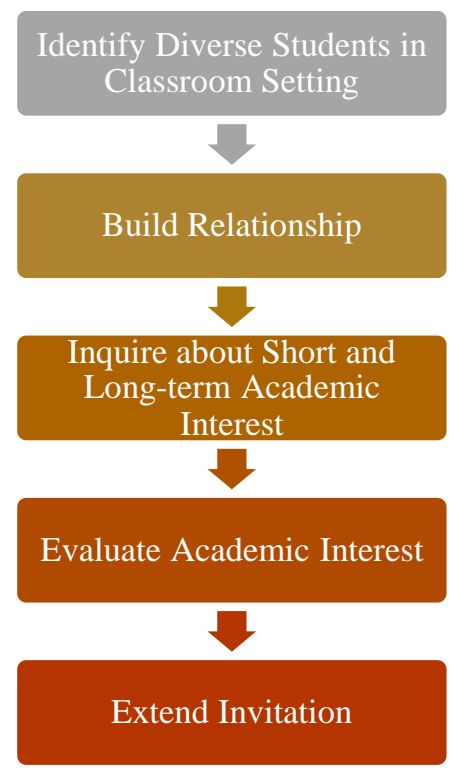

Figure 1. Proposed Recruitment Strategy for Underrepresented Minorities - IBIEE Model

This recruiting strategy represents an alternative and practical solution to the current norm in which undergraduate students actively search for research opportunities. Instead, faculty members play a pivotal role in engaging, motivating, and supporting the growth and development of underrepresented students. The authors believe that such strategy has the potential to enhance the staggering number of underrepresented groups in STEM related fields, graduate school, and faculty ranks. 
As far as incorporating the IBIEE model, it is highly recommended, but not necessary, that the focal point of recruitment effectuates within a classroom setting given that faculty members exercise a higher communication role with undergraduate students. Thus, the first component of the recruiting strategy requires for the instructor to be attentive to the number of underrepresented students enrolled in class such that potential candidates interested in participating in research venues may be identified. It is not sufficient for faculty members to solely partake in instructional efforts. Being attentive and receptive to the classroom audience are strategic elements which will encourage a rapport between faculty and students. As a result, it is imperative for the faculty member to initiate the process by building a relationship with underrepresented students prior to extending any sort of invitation.

Thus, the second component of the proposed model recommends establishing a consistent form of communication with the students as it may take time to nurture an acquaintance. Thus, instructors are suggested to build a rapport with students prior, during, or after instructional sessions. It can be a simple greeting that stimulates conversation, or an inquiry about a theme covered in class, or a random activity occurring on campus. The objective is to simply engage in conversation with the students regardless of the context to eliminate any intimidation barriers that may exist. Building such relationships represents a crucial component in the recruitment process as it promotes a stronger sense of belonging and higher academic efficacy.

Once a respectable relationship has been developed, the proposed recruitment model recommends that faculty members inquire about short-term and long-term academic goals. It can be regarding career intentions, internship resources, potential employment opportunities, graduate school, and most importantly, undergraduate research opportunities. Such interaction will serve not only to establish a stronger communication channel, but as an assessment tool to determine whether the student has the aptitude and desire to conduct undergraduate research. If the student displays any sort of interest in the latter, the proposed model suggests that the faculty member outlines the immediate and long-term academic and professional benefits of conducting undergraduate research. This action is immediately proceeded by the faculty member delineating the type of research efforts conducted in his/her group and extending an informal invitation to the student.

The proposed recruiting strategy goes beyond the current programs and initiatives created by federal and private agencies that attract underrepresented minorities to undergraduate research venues [6], [19], [20]. For those underserved students who are unaware of research opportunities, or consider themselves incompetent of performing research, such recruitment strategy is the channel to identify hidden talent and foster inclusion, development, and mentorship. In the process of performing academic research, the faculty member serves as a mentor by providing extensive technical guidance and offer emotional support to strengthen academic development while simultaneously advocating post-graduation career venues.

\section{METHODS AND ANALYSIS}

This research draws from a social constructivist theory that is based on the belief that all knowledge is socially constructed and mediated by historical and cultural factors [2]. Contemporary views and practical applications of social constructivism is a learning theory and pedagogical approach that is rooted in the work of psychologist Lev Vygotsky. According to Vygotsky, (1978) "Education is realized through the students' own experience, which is wholly determined by the environment and the role of the teacher then reduces to directing and guiding the environment 
(p.50)." This theoretical position posits that the instructor has a significant influence in shaping the learning experiences of learners and serves as a critical role to foster the intellectual and cognitive development of students.

In this study, the proposed IBIEE model was piloted with various undergraduate students conducting research under the supervision of the corresponding author in Mechanical Engineering. The authors utilized a self-developed, small survey instrument, which was electronically administered via Qualtrics to eleven students enrolled in small private university in Texas, to inquire into the effectivity of the suggested recruiting model. The participant demographics, displayed in Table 1, consisted of one female and ten male students, eight of which identified as underrepresented minorities.

Table 1: Student Demographics of Piloted Study

\begin{tabular}{lcc}
\hline Variable & Total & Percentage \\
\hline Gender & 1 & $9.09 \%$ \\
Females & 10 & $90.01 \%$ \\
Males & & \\
Race/Ethnicity & 0 & $0 \%$ \\
American Indian or Alaska Native & 1 & $8.33 \%$ \\
Asian & 1 & $8.33 \%$ \\
African American & 6 & $50 \%$ \\
Hispanic/Latina/o & 0 & $0 \%$ \\
Native Hawaiian/Pacific Islander & 3 & $25 \%$ \\
White & 1 & $1.89 \%$ \\
Other & & \\
\hline
\end{tabular}

The administered survey consisted of three segments. The first involved inquiring how undergraduate students joined the piloted research group to determine which sought an opportunity, which were invited by current/past group members, and which were recruited by the faculty advisor. For those students being recruited by the faculty advisor, it was critical to determine the number of underrepresented minorities participating in such venues and verify the suggested IBIEE model. As such, three options were specified on the survey:

1. Actively sought an opportunity

2. Invited by a past or current member

3. Invited by faculty advisor 
The second segment of the administered survey targeted the implementation of the IBIEE model components to recruit students. In this regard, two open-ended questions were utilized to inquire about the disposition from the faculty advisor to proactively identify and recruit engineering students into the research group. The questions posed on the survey were the following:

1. Prior to receiving an invitation to participate in research, did you have a good relationship with the instructor?

2. Did at any point prior to receiving an invitation to participate in research, did the instructor ask you about your short or long-term plans?

In the process of performing undergraduate research, the faculty member serves as a mentor by providing extensive technical guidance and offer emotional support to strengthen academic development while simultaneously advocating post-graduation career venues. These academic resources are necessary components for securing employment post-graduation or establishing fundamental research knowledge for graduate school. As such, the third segment of the administered survey involves inquiring about the mentoring role the faculty advisor plays once underrepresented minorities join the research group. For this case, one open-ended question was utilized:

1. At any point have you talked to your faculty advisor about post-graduation career venues?

Descriptive statistics were employed for analysis and presentation of data results. The authors note the following limitations of the study: (a) small sample size; (b) self-developed survey instrument; (c) convenient sampling procedure.

\section{RESULTS}

\section{$\underline{\text { Case } 1}$}

The first segment of the administered survey inquired how undergraduate students joined the piloted research group. The survey responses consisted of three items: actively sought an opportunity; invited by current/past group members; recruited by the faculty advisor. Primary results, as displayed in Table 2, indicate that $63.64 \%$ of the students on the piloted research group actively sought an opportunity to engage in undergraduate research, while $36 \%$ of the participants were invited by the faculty advisor. None of the undergraduate students in the group were invited by a past or current members.

Table 2. Student Responses

\begin{tabular}{lcc}
\hline Survey Items & N & Percentage \\
\hline Actively sought an opportunity & 7 & $63.64 \%$ \\
Invited by a past or current & 0 & $0.00 \%$ \\
member & 4 & $36.36 \%$ \\
Invited by faculty advisor & 4 & $100 \%$ \\
\hline Total & 11 & \\
\hline
\end{tabular}


For those students being recruited by the faculty advisor, it was critical to determine the number of underrepresented students participating in research. Results indicate that the four students (100\%) recruited were identified as underrepresented students, which nurtures a desire from faculty advisor to proactively recruit engineering students into the group. This statistic is a critical finding that has profound implications for students, especially those from underserved and underrepresented communities.

\section{Case 2}

The second segment of the administered survey targeted the implementation of the model components to recruit students. In this regard, two open-ended questions were utilized to inquire about the disposition from the faculty advisor to proactively identify and recruit engineering students into the research group.

\section{Importance of Relationships}

Based on the first open-ended question, students shared relevant information about being actively recruited to explore and participate in research-oriented opportunities. Several indicated that the professor established a consistent form of communication prior, during, or after instructional sessions. When addressing the relational aspect of the invitation one student shared following statement:

"I had a good relationship with the instructor before being invited to participate in research. Though I was a new student, the instructor was very amicable and available to any questions or inquiries I had, both after class and during office hours. He really cared about both my professional growth as an engineer and my personal growth as a student throughout the time prior to the invitation."

Other students echoed the comments shared above by stating the following:

"I originally joined because I had an internship opportunity fall through at the last moment right before the summer. I was looking for something productive to do over the summer and decided to speak with Dr. Z. I had previously been in a couple classes with Dr. $Z$ and felt that I had a good relationship with him so I asked him if there were any opportunities with him over that summer. He said yes and I was decided to continue to work with him past that summer because I was interested in the work that we were doing."

"Before receiving the invitation to participate in research, I had a good relationship with my instructor. I had regular conversations with him. We would discuss both extracurricular and curricular topics. It was very common for my instructor to greet me first both inside and outside of class."

Another student shared the following statement:

"Prior to research, my instructor was always very welcoming and encouraged communication in and out of the classroom. Dr. Z made me feel incredibly valued 
not just as a student, but as a future engineer. Furthermore, I can say my instructor is largely responsible for cementing my choice to major in mechanical engineering. "

These statements highlight the importance of faculty members proactively developing meaningful relationships with students to support their intellectual and social development. A simple, intentional conversation regardless of its context eliminates any intimidation barriers that may exist. Building such relationships represents a crucial component in the recruitment process as it promotes trust, a stronger sense of belonging, and higher levels academic efficacy. Additionally, a strong rapport offers social and moral support to help unleash students' creative capabilities.

\section{Inquiring about Short and Long-term Goals}

The second open-ended question explored student experience regarding short and long-term goal considerations and prospects. The survey question stated the following: Did at any point prior to receiving an invitation to participate in research, did the instructor ask you about your short or long-term plans? This may include conversation about summer internships, employment, research, etc. Explain. In this regard, two students on the piloted research group offered the following reflections:

"My instructor asked me about my summer internship. During our discussion, it was noted that the knowledge and experience that I had gained from my summer internship would translate well to my instructor's research. The prospect of research was realized through these discussions about internships and employment."

"Dr. Z made a point to seek out internships and research in order to further our careers as engineers. In one-on-one conversations, topics ranged from academia to various life experiences."

The preceding student responses display the relevance of inquiring about short and long-term goals, particularly, summer internships. Such inquiries may lead to the identification of unexpected talents, interests, or experiences the student may have or has acquired. It was noted by the first comment that the summer internship experience translated well to the instructor's research. Such interaction served as an assessment tool to determine the aptitude and desire of the student to conduct undergraduate research. The remarks shared by the students further substantiates the pivotal role the faculty members play in recruiting, motivating, and supporting the growth and development of underrepresented students.

\section{Case 3}

The third segment of the administered survey inquired about the mentoring role the faculty advisor played once underrepresented students joined the research group. In such process, the faculty member serves as a mentor by providing extensive technical guidance, role modeling approaches to problem solving, and advocating post-graduation career venues. These academic resources are necessary components for securing employment post-graduation or establishing fundamental research knowledge for graduate school. 


\section{Post-graduation Instruction}

Based on the open-ended question, students shared relevant information about receiving guidance relating to Mechanical Engineering curriculum, undergraduate resources, summer internships, and graduate programs. One student, in particular, alluded that the faculty advisor invested time in explaining the benefits of pursuing an advanced degree and the aspects associated with attending graduate school. The following statement was shared:

"Dr. Z provided helpful information on the prospects and benefits of graduate programs."

Another student commented on the faculty advisor providing mentorship with industry related topics during his undergraduate research experience, which led to a summer internship opportunity and ultimately to a full-time offer:

"Being a part of his oil-industry research granted me the opportunity to obtain an internship with Chevron, which led to a full-time offer. Dr. Z was always available as a mentor for questions and guidance regarding graduate studies, research, and the professional industry."

The last student received diversified mentorship in areas such as Mechanical Engineering curriculum, graduate school, and undergraduate opportunities. The following comment was made:

"The mentoring I received from Dr. Z included advice about mechanical engineering, grad school, and undergraduate academics in response to any questions I brought him."

These comments reveal the posture of the faculty member to proactively identify and recruit underrepresented students into research venues through building a positive rapport and inquiring about short and long-term academic interest. They also illustrate the willingness of the faculty member to provide extensive mentorship regarding summer internships, graduate school, undergraduate opportunities, and industry related topics such that academic development is strengthen and post-graduation career venues are explored and advocated.

\section{CONCLUSION}

A strong STEM workforce is contingent on developing policies, programs, and initiatives that work to provide equitable access and opportunities for all students, especially those from underrepresented and underserved communities. This commitment to diversifying the STEM workforce will require deep commitment at all levels. Regardless of policy or reform efforts to drive significant change in the STEM fields, faculty members have a tremendous influence in shaping the engineering landscape. As such, the active recruitment and mentoring by faculty advisors is critical in engaging underrepresented students in research opportunities, which can have a profound impact on retention, persistence, and post-graduation outcomes such as pursuing graduate school and research-oriented opportunities [8]. The proposed IBIEE model presented by the authors offers faculty members a simple, yet practical and powerful strategic approach to 
engaging students in undergraduate research opportunities and contribute the advancement of equity in the STEM fields.

\section{Ongoing and Future Plans}

The proposed IBIEE model in this paper was piloted by a single faculty member. However, this model can exert a greater impact if faculty collaboration is accounted when recruiting underrepresented students to their respective labs. The authors are in the process (Phase 2) of developing an agenda to create survey data and organize focus group interviews with underrepresented students conducting undergraduate research in general. The objective is to assess the process of attaining their research position. In this regard, focus group interviews will be utilized to facilitate collective reflection and dialogue by providing students opportunities to openly discuss their learning experiences with fellow peers.

Resultantly, Phase 3 of this long-term project involves developing communication channels with faculty in the school of engineering who have underrepresented minorities conducting research under their supervision in order to assist each other in identifying and recruiting more students.

\section{REFERENCES}

[1] Russell, S. H. (2006). Evaluation of NSF support for undergraduate research opportunities: Follow-up survey of undergraduate NSF program participants: Draft final report (pp. vi, 6, 54, 15 p.). Arlington, VA: National Science Foundation.

[2] S Hurtado, K Eagan, T Figueroa, B Hughes. Reversing Underrepresentation: The Impact of Undergraduate Research Programs on Enrollment in STEM Graduate Programs. Los Angeles: Higher Education Research Institute, 2014.

[3] Russell SH, Hancock MP, McCullough J. The pipeline. Benefits of undergraduate research experiences. Science. 2007;316(5824):548-549.

[4] Gregerman, S. (1999) Improving the Academic Success of Diverse Students Through Undergraduate Research." Council on Undergraduate Research Quarterlv, 20. 5459.

[5] Petrella, John K and Alan P Jung. "Undergraduate Research: Importance, Benefits, and Challenges" International journal of exercise science vol. 1,3 91-95. 15 Jul. 2008.

[6] National Science Foundation, \& National Center for Science and Engineering Statistics. (2013). Women, Minorities, and Persons with Disabilities in Science and Engineering: 2013. Arlington, VA.

[7] Hurtado, S., Eagan, K., \& Hughes, B. (2012). Priming the Pump or the Sieve: Institutional Contexts and URM STEM Degree Attainments. Paper presented at the Annual Forum of the Association for Institutional Research, New Orleans, LA.

[8] Byars-Winston, A.M., Branchaw, J., Pfund, C., Leverett, P., and Newton, J. (2015). Culturally diverse undergraduate researchers' academic outcomes and perceptions of their research mentoring relationships. International Journal of Science Education, 37(15), 2533-2554.

[9] Lopatto, D. (2004). Survey of Undergraduate Research Experiences (SURE): First Findings. Cell Biology Education, 3(4), 270-277. 
[10] Gasiewski, J., Garcia, G., Herrera, F., Tran, M., \& Newman, C. (2010). Barricades, Bridges, and Programmatic Adaptation: A Multi-campus Case Study of STEM Undergraduate Research Programs. Paper presented at the Annual Forum of the Association for Institutional Research, Chicago, IL.

[11] Funk, C., Parker, K. Pew Research Center, January 2018. "Women and Men in STEM Often at Odds Over Workplace Equity"

[12] Status and Trends in the Education of Racial and Ethnic Groups. U.S. Department of Education. July 2010.

[13] Chavous, T., Leath, S., Gámez, R. Climate, Mentoring, and Persistence Among Underrepresented STEM Doctoral Students. Higher Education Today. American Council on Education. 2018.

[14] Carter, F. D., Mandell, M., \& Maton, K. I. (2009). The Influence of On-Campus, Academic Year Undergraduate Research on STEM Ph. D. Outcomes: Evidence from the Meyerhoff Scholarship Program. Educational Evaluation and Policy Analysis, 31(4), 441-462.

[15] Sadler, T. D., Burgin, S., McKinney, L., \& Ponjuan, L. (2010). Learning Science Through Research Apprenticeships: A Critical Review of the Literature. Journal of Research in Science Teaching, 47(3), 235-256. doi: 10.1002/tea.20326.

[16] Lopatto, D. (2007). Undergraduate Research Experiences Support Science Career Decisions and Active Learning. CBE-Life Sciences Education, 6(4), 297-306.

[17] Villarejo, M., Barlow, A. E., Kogan, D., Veazey, B. D., \& Sweeney, J. K. (2008). Encouraging minority undergraduates to choose science careers: career paths survey results. CBE-Life Sciences Education, 7(4), 394-409.

[18] Pew Research Center (2018). Women and men in stem often at odds over workplace equity. Retrieved from http://www.pewsocialtrends.org/2018/01/09/women-and-men-in-stem-often-atodds-over-workplace-equity/.

[19] DeHaan, R. L. (2005). The Impending Revolution in Undergraduate Science Education. Journal of Science Education \& Technology, 14(2), 253-269. doi: 10.1007/s10956-005-4425-3.

[20] Strayhorn, T. L. (2010). Undergraduate research participation and STEM graduate degree aspirations among students of color. New Directions for Institutional Research, 2010(148), 85-93.

[21] National Research Council. 2013. Preparing the Next Generation of Earth Scientists: An Examination of Federal Education and Training Programs. Washington, DC: The National Academies Press. https://doi.org/10.17226/18369.

[22] Mogk, D.W. Undergraduate research experiences as preparation for graduate study in geology. J. Geol. Educ. 1993;41:126-128.

[23] Tomovic, M.M. Undergraduate research — prerequisite for successful lifelong learning. ASEE Annu. Conf. Proc. 1994;1:1469-1470.

[24] Nagda B.A., Gregerman S.R., Jonides J., von Hippel W., Lerner J.S. Undergraduate studentfaculty partnerships affect student retention. Rev. Higher Educ. 1998;22:55-72. 
[25] Hathaway R.S., Nagda B.A., Gregerman S.R. The relationship of undergraduate research participation to graduate and professional education pursuit: an empirical study.

[26] Kremer J.F., Bringle R.G. The effects of an intensive research experience on the careers of talented undergraduates. J. Res. Dev. Educ. 1990;24:1-5.

[27] Bauer K.W., Bennett J.S. Alumni perceptions used to assess undergraduate research experience. J. Higher Educ. 2003;74:210-230.

[28] Office of Academic Advising. Presented at Divisional Engineering Advising Session. 2019. 